\title{
SUPERVISI AKADEMIK KEPALA SEKOLAH TERHADAP KINERJA GURU DALAM MENINGKATKAN KOMPETENSI GURU SMK
}

\author{
Edi Suratno ${ }^{1}$, Marzuki Noor $^{2 *}$, Riyanto $^{3}$ \\ ${ }^{1}$ SMK Muhammadiyah Tulungagung \\ ${ }^{2,3}$ Universitas Muhammadiyah Metro \\ E-mail: $\quad$ edi.suratno30091985@gmail.com ${ }^{1)}$ \\ marzuki4metro@gmail.com $^{2 *}$ \\ riyantoto56@gmail.com ${ }^{3)}$
}

\begin{abstract}
Abstrak
Supervisi merupakan faktor penting dalam pelaksanaan perbaikan pendidikan dan pengajaran secara keseluruhan. Supervisi yang baik tentunya disertai dengan perencanaan dan pelaksanaaan yang baik. Penelitian ini memfokuskan pada Supervisi Akademik Kepala Sekolah terhadap Kinerja Guru dalam meningkatkan Kompetensi Guru SMK Muhammadiyah Gunung Agung Kabupaten Tulang Bawang Barat. Peneliti menggunakan pendekatan deskriptif kualitatif. Masalah yang akan diteliti mengetahui fenomena yang berkembang sebagai kesatuan yang diketahui secara utuh tanpa terikat oleh suatu variabel peneliti menggunakannya untuk memudahkan peneliti agar lebih dekat dengan subjek yang sedang diteliti dan lebih peka terhadap pengaruh berbagai fenomena yang terjadi di lapangan mengenai Kompetensi Guru SMK Muhammadiyah Gunung Agung Kabupaten Tulang Bawang Barat. Tindak Lanjut supervisi yang diperoleh guru setelah mengikuti supervisi bertambahnya pengalaman, meningkatkatnya wawasan, pengetahuan, keterampilan, dan mampu mengubah sikap dan penampilan yang selama ini masih kurang. Berdasarkan hasil penelitian tentang tindak lanjut supervisi akademik yang dilakukan oleh kepala SMK Muhammadiyah Gunung Agung adalah dalam bentuk program pengembangan dan peningkatan kompetensi guru. Sebagai tindak lanjut dari supervisi kepala sekolah membuat program untuk perbaikan dan pengembangan serta peningkatan kualitas dan kompetensi guru seperti mengadakan workshop pembuatan RPP, pembuatan karya tulis ilmiah, dan lain-lain. Kepala Sekolah melakukan pembinaan terhadap guru memiliki kinerja masih rendah serta memberikan pembinaan sampai ada perubahan yang lebih baik pada guru tersebut dan memberikan reward kepada guru-guru yang berprestasi.
\end{abstract}

Kata kunci: Supervisi Akademik1;Kinerja Guru2; Kompetensi Guru3.

\begin{abstract}
Supervision is an important factor in the implementation of overall improvement in education and teaching. Good supervision is of course accompanied by good planning and implementation. This study focuses on the Principal's Academic Supervision of Teacher Performance in improving Teacher Competence at SMK Muhammadiyah Gunung Agung, Tulang Bawang Barat Regency. The researcher used a qualitative descriptive approach. The problem to be studied is to find out the phenomena that develop as a unit that is known as a whole without being bound by a variable. The researcher uses it to make it easier for researchers to be closer to the subject being studied and more sensitive to the influence of various phenomena that occur in the field regarding the Competence of Teachers of SMK Muhammadiyah Gunung Agung. West Tulang Bawang Regency. Follow-up supervision obtained by teachers after participating in supervision increases experience, increases insight, knowledge, skills, and is able to change attitudes and appearances that have been lacking so far. Based on the results of research on the follow-up to academic supervision carried out by the head of SMK Muhammadiyah Gunung Agung, it is in the form of a teacher competency development and improvement program. As a follow-up to the supervision of the principal, the principal makes a program for improvement and development as well as improving the quality and competence of teachers, such as holding workshops on making lesson plans, making scientific papers, and others. Principals provide guidance to teachers who have low performance and provide guidance until there is a better change in the teacher and give rewards to teachers who excel.
\end{abstract}

Keywords: Academic Supervision 1; Teacher Performance 2; Teacher Competence3 


\section{PENDAHULUAN}

Kepala Sekolah sebagai pimpinan paling tinggi disekolah dianggap berhasil apabila bisa menambahkan cara kerja pendidik melewati beberapa wujud proses pembinaan pada kemampuan pendidik untuk melaksanankan kegiatan belajar disekolah. Supaya kepala sekolah wajib bisa melaksanakan fungsi serta bertanggungjawab menjadi administrator pendidikan, supervisor pendidikan, pemimpin pendidikanserta manajer pendidikan. Pada umumnya fungsi serta tugas Kepala Sekolah untuk Pengaturan Menteri Pendidikan Nasional Nomor 13 Tahun 2007 pada Standars Kepala Sekolah, dijelaskan bahwasanya Kepala Sekolah wajib mempunyai kompetensi kepribadiannya, kewirausahaan, manajerial, social serta supervise. Seluruh kompetensi ini wajib dipunyai pada Kepala Sekolah untuk bisa menciptakan kegiatan belajar yang bermutu untukkerangka tercapainya pendidikan yang memiliki kualitas disekolah.

Mutu pendidikan ditentukan pada faktor terpenting yakni:, proses, input, dorongan ruang lingkup serta sarana prasarana. Input (masukan) berkaitan dengan kondisi anak didik (minat, bakat, potensi, motivasi dan sikap) sementara kegiatan berhubungan pada pembuatan kondisi kegiatan belajar, banyaknya ditentukan dalam kreativitas pendidik. Dorongan ruang lingkup dihubungkan pada kondisikian menunjang kegiatan belajar, contohnya: lingkungannya dikeluarga, wargaserta alam sekitarnya. Sarana prasarana dalam hal ini merupakan perangkatnya yang memfasilitaskan kegiatan belajar untuk: gudang, alat laboraturium, komputer serta lainnya.

Dalam rangka meningkatkan mutu pembelajaran, maka supervisi penting untuk dilaksanakan.Supervisi yaitu faktor terpenting untuk terlaksananya remedial pendidikan serta pembelajaran dengan seluruhnya. Perkembangan kemampuan serta informasi pendidik bisa dilihat untuk suatu satu tujuan dilakukan supervisi untuk rangka peraihan evaluasi kualitas pendidikan serta pengajaran. Supervisi yang baik tentu disertai dengan perencanaan dan pelaksanaaan yang baik.

Realita kompetensi guru dalam proses pembelajaran hingga sekarang bermacammacam. Permasalahan yang berhubungan pada situasi pendidik dianatara lainnya, beberapa kemampuan pendidik pada kegiatan belajar serta pemahaman tentang informasi. Pendidik tidak bisa mengarahkan cara kerja profesionalitas. Maka memperlihatkan bahwasanya cara kerja pendidik tidak seluruhnnya didasari pada kuasa kompetensi ataupun kemampuan hinggaa terpenuhi, hal ini memicu dalam rendahnya cara kerja profesionalitas saat berencana, merancang, serta mengevaluasi kegiatan belajar. beberapa kali pendidik belum menyiapkan serta pemahaman atas menyusun perencanaan belajar. Pendidik yaitu sesuatu profesi, yang memiliki arti dalam tingkatan yang diperlukan kemampuan kusus untuk menjadi pendidik. Pendidik belum bisa dilaksanakan pada seluruh manusia diluar jenis pendidikan. Pendidik mempunyai fungsi yang paling penting saat menentukan kuantitas serta kualitas pengajaran yang dilaksanakan dengan terpenuhinya tanggung jawab, kesungguhan sabar serta teliti dikarenakan hal yang terjang bukansatu satunya wujud barangtak bergerak melain kan siswa yang telah menjalani perkembangan serta pertumbuhannya.

Kompetensi pendidik ini wajib ditingkatkan engan menerus untuk menciptakan pendidik yang memiliki kualitas serta profesionalitas. Pendidik untuk SDM yang terdapat disekolah wajib dengan memiliki inovasi serta kreative pada proses belajar serta pertumbuhan dirinya dalam memajukan kompetensi dengan individual. 
Kompetensi yang wajib mempunyai pendidik berlandaskan pasal 8 UU Republik Indonesia No.14 tahun 2005 tentang: kompetensi pedagiogik, kompetensi prilaku, kompetensi social serta kompetensi yang dihasilkan melewati pendidikan profesi.

Pendidik profesionalitas tak hanya memenuhi jenis ilmu, bahan ajar, serta methode yang baik, namunbisa untuk motivasi siswa, mempunyaikemampuan yang banyak serta pengetahuan yang tinggi dalam bidang pendidikan. Pada kompetensi pendidik, oleh hal ini pendidik masa depan tak nampak lagi bagai pendidik yang sedang mengajar (teachers), fungsiyang paling nampak saat ini, namun menjadi bagai pelatih (cooach), pembimbing (counselors), serta manajer pembelajaran(learniing managers) (Kunandar,2011:50). Maka ke kompetensi pendidik sangat diharapkan mendapatkan wadah terpenting dikalangan pendidikan, terbaik pada kepala sekolah, sesama guru serta staf sekolah, siswa serta orang tua dalam menambah kualitas SDM terbaik pada segi akhlak ataupun padawujud kompetensi menjadi guru.

Pada hal ini, proses supervisi academik menjadikan kewajiban dalam menambah kompetensi pendidik pada kegiatan belajar serta pertumbuhan pendidikan yang makin cepat, dituntutnya pendidik menjadikan orang yang bertumbuh juga disetiap tahunnya serta makin profesionalitas saat mengajari, hingga supervisi academik bisa dilaksanakan dengan efektive untuk kekurangan pada pendidik serta terlaksananya supervisi pula bisa langsung diatasi.

Dari hasil pengamatan pada tanggal 1 September 2020 sampai dengan tanggal 11 September 2020 di SMK Muhammadiyah Gunung Agung. Di lihat dari Kepala Sekolah dalam menjalankan aktivitas sekolahnya cukup disiplin. Tampak pada aktivitas dan kedisiplinan seperti jam masuk dan jam pulang sekolah selalu tepat waktu. Kepala Sekolah turut mengingatkan kepada para dewan guru nya untuk selalu disiplin dan menghargai waktu.

\section{METODE PENELITIAN}

Penelitian tersebut terfokus dalam Supervisi Akademik Kepala Sekolah pada cara kerja pendidik untuk menambah Kompetensi pendidik SMK Muhamadiyah Gunung Agung Kabupaten Tulang Bawang Barat. Dalam penelitian tersebut, peneliti memakai pendekatan kualitatif untuk prosedur. Peneliti memakai pendekatan deskriptif kualitatif, bahwasanya Pendekatan kualitatif yaitu proses penelitian yang menghasilkan data deskriptif tentang kata ataupun tulisan serta lisan pada seorang serta prilaku yang sudah diamati (Moleong, 2000: 3).

Pada teori Reinforcemens yakni teori yang mempelajari prilaku seseorang apabila dihadapkan dalam suatu konsekuensi. Pada hasil penelitian disimpulkan bahwasanya sikap bisa dibentuk melewati ruang lingkup sesudah terdapatnya penguatan berapa kali. Teori tersebut dilandaskan pada macam hukuman terpengaruh dimana perilaku pada konsekuensi terbaik cenderung agar terulang, sementara perilaku pada konsekuensi buruk cenderung dalamtak terulang. Teori ini berfokus sepenuhnya padaapa yang terjadi dalam individual saat dia mengambil tindakan. Teori tersebut yakni alat yang kokoh dalam menganalisisabermekanisme pengendalian dalamtingkah laku individual (Sundawi 2018).

Pendekatan tersebut bisa dipilih padapermasalahan yang segera diteliti lebih dalamtentang proses sertamemakai pengamatan ataupun observasi dalamkeadaan 
tertentu serta penulis menginginkan suatu fenomena yang bertambah untuk kesatuan yang diketahui dengan utuh tidak terhubung pada sesuatu variabel ataupun hipotesa tertentu secara methode penelitian, penulis menggunakannya agar memudahkan penulis untuk bisa dekat pada subjek yang akan diteliti serta lebih peka pada pengaruh beberapa kejadian yang terlaksana dilapangan tentang Kompetensi pendidik SMK Muhamadiyah Gunung Agung Kabupaten Tulang Bawang Barat.

\section{HASIL DAN PEMBAHASAN}

\section{Perencanaan Pelaksanaan Supervisi Akademik}

Supervisi yang dilakukan pada kepala sekolah dalam dasarnya telahpositif. Dengan adanya supervisi yang dilakukan pihak sekolah dengan langsung akan berpengaruh pada kinerja mengajar terutama didalam pencapaian target dalampeserta didik. Pada pelaksanaan supervisi akademik kepala sekolah memakai pendekatan langsung (direktif) serta pendekatan tak langsung (non direktif). Pendekatan langsung (direktif) yakni cara pendekatan padapermasalahan yang memiliki sifat langsung/ memberi arahan langsung. Pendekatan tak langsung (non direktif) yakni supervisor tak langsung menunjukakan permasalahan nya, namundia sudah dulu mendengarkan dengan aktif pada yang dikemukanan pendidik. Kepala sekolah saat melakukan supervisi menganggap seluruh pendidik serta bawahnya yaitu dianggap untuk kesatuan keluarga, hingga saat pelaksanaan supervisi yang diberikan kepala sekolah pada pendidik tak menjadikan pendidik merasakan ditegur, tak merasakan diajarinya hingga menumbuhkan rasa melengkapinya serta kegiatan pembelajaran bersamaan.

Berlandaskan paparan diatas mampu disimpulkanoleh penulis pada kepala SMK Muhamadiyah Gunung Agung mengadakannya supervisi akademik pada beberapa cara, dalam supervisi melalui rapat dewan guru dilakukan pada awal semester, tujuannya untuk menyusun program serta perangkat kegiatan belajar yang akan digunakan untuk kegiatan belajar, sementara dalam kunjungan kelas, observasi kelas, serta pembicaraan individu dilakukan disela-sela waktu kegiatan belajar serta waktu luang.

\section{a. Melalui Rapat Dewan Guru}

Supervisi agar meningkatkan Kompetensi pendidik di SMK Muham/madiyah Gunung Agung dilaksanakan kepala sekolah melewati rapat dewan pendidik yang dilakukan dengan rutin dalam tiap awal bulan. Rapat yang selalu dilakukan dalam tiap awal bulannya agar memberikan informasi serta evaluasi program yang udah berjalan ataupun program yang akan dilakukan diwaktu mendatang. Pada pelaksanaan nya kepala sekolah dibantupada wakil kepala sekolah jenis kurikulum serta di laksanakan tiap minggu pertama tiap bulannya.

\section{b. Kunjungan Kelas}

Saat melaksanakan perannya dalam supervisor, kepala SMK Muhamadiyah Gunung Agung melaksanakan kunjungan kelas agarbisa melihat secara langsung kegiatan pendidik melakukan pembelajaran dikelas. Pada tekhnik tersebut, Kepala Sekolah akan memperhatikan sertamemberi nilaidengan langsung pelaksananan kegiatan belajar, mulai pada cara pendidik membuka kegiatan belajar, pengelolaan dikelas, penguasaan materi, penerapan metode serta media yang tepat, evaluasi serta cara menutup kegiatan belajar. 


\section{c. Observasi Kelas}

Observasi kelas dilaksanakannya kepala sekolah hanya agar mengetahui situasi kegiatan belajar yang dilaksanakanpada pendidikdidalam kelas. Observasi kelas membutuhkan waktu yang relatif sedikit dibandingkan pada kunjungan kelas.

\section{d. Pembicaraan Individual}

Saat terlaksananya supervisi dalam meningkatkan Kompetensi pendidik, kepala sekolah bisa menerapkan pertemuan individualserta pendidik. Pertemuan Individual bisa dilaksanakan dengan formal ataupun dengan nonformal. Dengan formal pembicaraan individual berlangsungkan diruang kepala sekolah dalam diskusi pada masalah yang dihadapi padapendidik, baik yang berhubungan pada program ataupun agar terlaksananya kegiatan belajar.

\section{2) Pelaksanaan Supervisi Akademik}

Pelaksanaan supervisi akademik berfokus dalam kegiatan belajar hingga pelaksanaannya mempunyai tahapan yang perlu dilalui. Sebelum melaksanakan supervisi kepala sekolah sudah mensosialisasikan terlebih pada metode serta cara terlaksananya supervisi yang sudah dilakukan kepala sekolah.

\section{3) Evaluasi Supervisi Akademik}

Evalusi supervisi akademik yaitu pemberi estimasi pada proses supervisi dalam menentukan efektifitas serta kemampuan pada pencapaian tujuan supervisi yang sudah ditetapkan. Proses evaluasi memiliki tujuan dalam mengerti tingkatanberhasilnyasesuatu pelaksanaan, selain itu bisa dipakai untuk dasar tumpuan dalam proses berikutnya.

\section{4) Tindak Lanjut hasil Supervisi}

Tindakan yang didapatkan pada proses supervisi bisa dilihat sesudah pendidik mengikuti kegiatan supervisi, misalnya cara mengajar guru. Apakah guru mengalami perubahan dalam melaksanakan tugasnya. Besar kecilnya perubahan kinerja guru setelah mengalami supervisi sesuai dengan kompetensi yang dimiliki guru tersebut, karena kompetensi yang dimiliki guru berbeda-beda.

\section{Peningkatan Kompetensi Guru}

Pada mendefinisikan pendidik yang profesionalitas kepala sekolah memiliki pendapat bahwasanya pendidik profesionalitas yaitu pendidik yang terbaik, awal pada rencana, terlaksananya hingga pada pengevaluasian. Beberapa usaha sudah dilaksanakan kepala sekolah dalam menambah Kompetensi pendidik.

\section{Hambatan Dalam Pelaksanaan Supervisi Akademik}

Hambatan yang sering ditemui selama terlaksananya supervisi yaitu waktu pelaksanaan supervisi, guru merasa terbebani ketika disupervisi, perangkat pembelajaran yang belum lengkap, serta penggunaan media pembelajaran yang belum maksimal.

\section{KESIMPULAN DAN SARAN}

Berlandaskan tujuan serta hasil analisis data yang sudah dilaksanakan, bisa disimpulkan Supervisi Akademik Kepala Sekolah pada kinerja guru untuk meningkatkan Kompetensi Pendidik, sudah dilakukan dengan baik oleh Kepala SMK Muhammadiyah Gunung Agung. Dalam pelaksanaan supervisi akademik Kepala SMK Muhammadiyah Gunung Agung menggunakan tekhnik yakni rapat dewan pendidik, berkunjung dikelas, observasi dikelas serta pembicaraan individual. Tingkat 
keberhasilan supervisi dapat dilihat dari hasil evaluasi pelaksanaan supervisi. Kepala SMK Muhammadiyah Gunung Agung selalu melakukan evaluasi setelah pelaksanaan supervisi akademik tujuannya dalammengolah menjadi lebih baikcara kerjapendidik yang masih kurang serta mempertahankan yang telah positif.

\section{DAFTAR PUSTAKA}

Arifin, I. (2010). Kompetensi Guru sebagai wacana dalam Reformasi pendidikan. Simposium Nasional Pendidikan Universitas Gajah Mada

Departemen Pendidikan Nasional. (2007). Pendidikan dan Pelatihan: Supervisi Akademik dalam Peningkatan Kompetensi Guru. Jakarta: Depdiknas.

Juhri, AM. (2018). Supervisi Pendidikan. Lampung: Laduny.

Karwati Euis dan Doni Juni Priansa. (2013). Kinerja dan kompetensi kepala Sekolah. Bandung : AlfaBeta

Kunandar. (2011). Guru Profesional: Implementsi kurikulum Tingkat Satuan Pendidikan dan Suksess Dalam Sertifikasi Guru. Jakarta : Raja Grafindo Persada.

Latunaka. (2010). Pengamatan Dalam Penelitian, Data dan Metode Penelitian. Jogjakarta: Diva Press.

Leniwati. (2017). Implementasi Supervisi Akademik Kepala Sekolah Untuk Meningkatkan kinerja Guru. Jurnal Manajemen, Kepemimpinan, dan Supervisi Pendidik. Volume 2. No.1 Juni 2017.

Masaong Abd, Kadim. (2013). Supervisi pembelajaran dan pengembangan kapasitas guru. Jakarta : Alfabetha.

Miles, Stephen, dkk. (2009). Analisis Data Penelitian: Perilaku Organisasi-Konsep, Jakarta: PT. Prenhallindo.Moleong,

Mukhtar., dkk. (2009). Orientasi Baru Supervisi Pendidikan. Jakarta: Gaung Persada.

Mulyasa, E. (2011). Kompetensi Guru. Bandung: PT. Remaja Rosdakarya.

Nurjaman. (2014). Manajemen Personalia dan Aplikasinya. Jakarta: Bina Aksara. UNY

Hamalik Oemar. (2006). Pendidikan Guru berdasarkan Pebdekatan kompetensi. Jakarta : Bumi Aksara 
Peraturan Menteri Republik Indonesia No. 16 tahun 2007 tentang Kualifikasi Akademik dan Kompetensi Guru Kementrian Pendidikan Nasional. 2007. Jakarta: Kemendiknas.

Pidarta, Made. (2009). Supervisi Penidikan Kontekstual. Jakarta: Rineka Cipta.

Purwanto, M. Ngalim. (2008). Administrasi dan Supervisi Pendidikan . Bandung: PT. Remaja Rosdakarya.

Prasojo Lantip Diat., dkk. (2011). Supervisi Pendidikan. Yogyakarta: Gava Media.

Sagala, Syaiful. (2011). Supervisi Akademik Kepala Sekolah. Bandung: Alfabeta

Sagala, Syaiful. (2012). Supervisi: Tujuan dan fungsi Supervisi. Bandung: Alfabeta

Sahertian, Piet A. (2008). Supervisi Pendidikan. Jakarta: Rineka Cipta.

Samsudin, Sadili. (2006), Manajemen Sumber Daya Manusia, cetakan ke-1 Bandung : Pustaka Setia

Sugiono. (2009). Metode Penelitian Kuantitatif, Kualitatif dan $R \& B$. Bandung: Alpa Beta.

Suharsaputra, Uhar. (2010). Administrasi Pendidikan. Bandung: PT. Refika Aditama.

Sulistyorini. (2001). Pengembangan Evaluasi Diri Guru dalam Sekolah Bandung: PT. Refika Aditama.

Sundawi, Muhammad. (2018). Teori Penguatan: reinforcement theory of motivation. Bandung: PT. Remaja Rosdakarya.

Supardi. (2014). Supervisi: Arti dan Peningkatan Supervisi. Yogyakarta: Irgisod.

Suryosubroto. (2010). Manajemen Pendidikan di Sekolah. Jakarta: Rineka Cipta

Syaifudin Saud, Udin. (2009). Pengembangan Profesi Guru. Bandung: Alpa Beta.

Swaringen Midred E. (2015). Observasi Pembelajaran: PeningkatanMutuPendidik di Indonesia. Jakarta: Rajawali Press.

Undang-Undang Republik Indonesia No. 14 Tahun 2005. Tentang Guru dan Dosen. Jakarta. Depdiknas.

Undang-Undang Republik Indonesia No. 20 Tahun 2003. Tentang Sistem Pendidikan Nasional (SIKDINAS). Jakarta. Depdiknas. 